\title{
FAMÍLIAS E ACESSO DIFERENCIADO A ESCOLAS PÚBLICAS PRESTIGIADAS: UM ESTUDO DE CASO'
}

\author{
Márcio da Costa*
}

RESUMO: Este trabalho traz resultados de uma pesquisa realizada em escolas municipais da cidade do Rio de Janeiro que desfrutam de reputações contrapostas. Foram realizadas observações, entrevistas e surveys em três pares de escolas, em regiões distintas da cidade, segundo critério de demanda por parte da população e de prestígio diante da burocracia educacional. A pesquisa busca conhecer mecanismos pelos quais a reputação das escolas se constrói e mantém, com base na percepção de que essa reputação é relevante na distribuição de oportunidades escolares e se associa intimamente a fatores de estratificação social. Hierarquias são destacadas em um ambiente que é tradicionalmente pensado como homogêneo: as escolas "comuns" das redes públicas. A literatura pertinente é trazida, especialmente aquela que trata de escolhas escolares e de diferenciação entre e intraescolas. Neste artigo, foram selecionados resultados que destacam a força dos condicionantes familiares na compreensão do fenômeno em foco.

Palavras- chave: Escolha Escolar; Hierarquias Escolares; Quase-mercado Educacional; Oportunidades Educacionais; Sociologia da Educação; Sistemas Educacionais.

\section{FAMILIES AND DIFFERENTIATED ACCESS TO HIGH-PRESTIGE PUBLIC SCHOOLS:}

\section{A CASE STUDY}

ABSTRACT: The article brings up results from a piece of research carried out in six municipal schools holding opposed reputations. We accomplished structured observations, interviews and questionnaires in three very different areas of Rio de Janeiro. The demand for the schools and the perception of the educational bureaucracy were the criteria for their school's selection. The research seeks to understand how the school prestige arises and is sustained, considering that this prestige is a relevant factor for the distribution of educational opportunities and is strongly tied to social hierarchies and stratification. We highlight hierarchies and social inequalities within social contexts that are usually thought of as homogenous: the "ordinary" public schools. The pertinent literature was reviewed with special attention to school choice and segmentation among and within schools. Some results were selected stressing the strength of the family conditioning to help comprehending the phenomenon under our focus.

Keywords: School choice; School Hierarchies; Educational Quasi-market; Educational Opportunities; Sociology of Education; Educational Systems.

\footnotetext{
* Doutor em Sociologia pelo Instituto Universitário de Pesquisas do Rio de Janeiro (IUPERJ) e Docente da Faculdade de Educação da Universidade Federal do Rio de Janeiro (UFRJ). E-mail: marccosta@terra.com.br
} 
Este artigo apresenta resultados originais de uma pesquisa de campo concluída no início de 2007. O enfoque adotado procurará concentrar atenção sobre as relações entre hierarquias escolares e características familiares. Nada de original, considerando a longa tradição, especialmente anglosaxônica, em observar as imbricações entre elementos constitutivos da ordem familiar (culturais ou de composição) e rendimento/chances escolares. A questão das oportunidades sociais derivadas de atributos adquiridos socialmente tem sido chave no desenvolvimento do pensamento social contemporâneo. Afinal, especialmente em sociedades embaladas por um ethos meritocrático, o enigma da estabilidade relativa origem/destino social anima boa parte da sociologia, com destaque para a sociologia da educação e da estratificação social. De certa forma, pode-se afirmar que a sociologia da educação tem sido, ao menos nos últimos 50 anos, essencialmente uma sociologia da desigualdade social e há evidências sólidas da transmissão de vantagens e desvantagens sociais, de geração a geração, para além da herança de bens materiais.

Talvez, a originalidade e o interesse de nosso enfoque residam, no caso brasileiro, no esforço por compreender hierarquias e desigualdades no interior de um sistema escolar pretensamente homogêneo ou ao menos pouco reconhecido como palco de grandes disparidades: uma rede municipal de ensino. Apesar de adotar procedimentos de estudo de caso e, por conseguinte, não se prestar a inferências de caráter geral, sua intenção explícita é trazer conhecimento - empiricamente sustentado - que nos ajude a compreender a produção de desigualdades entre "pares", no âmbito da escolarização dos indivíduos.

Como inspiração conceitual, encontramos Elias e Scotson e seu trabalho Os Estabelecidos e os Outsiders, que aborda de maneira preciosa a produção e a manutenção de um senso de diferença - e dispositivos segregadores efetivos - entre grupos de indivíduos de uma localidade operária inglesa.

Há diferenças relevantes entre nosso objeto e a comunidade enfocada por Elias e Scotson. Afinal, nem mesmo estamos nos referindo a um universo social razoavelmente homogêneo, quanto à inserção nos espaços econômicos, como um povoado operário inglês dos anos 1960. Porém, o que nos interessa é o senso hierárquico compartido por um segmento social, tomado como indiferenciado sob muitos olhares sociológicos. A autoatribuição de superioridade por um grupo e as barreiras e 
interdições que promove, bem como a coesão interna nutrida em oposição ao grupo "inferior" e a busca de vantagens distintivas são aspectos que nos instigam. Não se trata, no estudo inglês, exatamente de uma oposição ou confronto grupal, à medida que o grupo "inferior" se caracteriza principalmente pela desarticulação e pela ausência de coesão interna, por uma identidade grupal amorfa, pela ausência de orgulho pela posição ocupada. Alguma vantagem posicional está na base dessa diferença. No caso inglês, o tempo de residência na região, diante de um fluxo migratório ocasionado por alterações econômicas.

Tratamos de hierarquias entre alunos de escolas públicas, tradicionalmente não observadas em suas grandes diferenciações. Essas hierarquias estão associadas a características socioculturais e escolares. A posição ocupada e a rede de laços sociais jogam papel relevante no acesso a determinadas oportunidades escolares que asseguram a seus portadores vantagens distintivas. Há unidades escolares que são bastante disputadas. Nesses estabelecimentos, há forte sentido de diferenciação diante das demais escolas da mesma rede. Seus integrantes parecem ter clara noção de que desfrutam de condições vantajosas, mobilizam recursos para preservar esse status, entre outros meios, ajustando seus comportamentos ao conjunto de expectativas recíprocas que compõem aquilo que se tem denominado "clima escolar". O acesso a esses estabelecimentos não ocorre de forma aleatória entre a população provável de frequentar escolas públicas. Colhemos indícios de que há acirradas disputas por algumas escolas públicas e que os mecanismos de seleção, apesar de formalmente inexistentes ${ }^{2}$, operam produzindo resultados de diferenciação na composição das escolas que vão além da distribuição espacial das desigualdades sociais.

Nosso estudo explora diversos aspectos, em uma tentativa multifocal, da vida e da configuração de seis escolas municipais do Rio de Janeiro, organizadas em pares geográficos diferenciados internamente, por serem escolas que gozam de reputações contrapostas em seus ambientes circundantes e diante da burocracia educacional ${ }^{3}$. Conforme dito, o recorte particular aqui realizado, considerando nossa temática, exporá achados referentes diretamente à dimensão familiar ou que podem ser razoavelmente a ela associados. Tais achados adquirem importância para nós à medida que se relacionam com as distinções entre as escolas e também intraescolares. 
Conforme apresentaremos, tanto família quanto meio circundante social parecem exercer papel relevante no tipo de agrupamento escolar a que se tem acesso, mas tais condicionantes convivem com outros conhecidos - as condições socioeconômicas e o capital cultural - além de outros menos referidos, em se tratando de uma rede pública municipal. O sistema escolar parece exercer papel destacado na construção dessas hierarquias, no processo de alocação de alunos a escolas e turmas, bem como seus usuários aparentam conhecer e manobrar com as hierarquias escolares.

Trataremos de tais questões recorrendo basicamente a dados quantitativos extraídos de um survey com estudantes das seis escolas. Dispomos, porém, e serão usados eventualmente neste trabalho, de informações colhidas em intenso processo de observação nas escolas e de realização de entrevistas com membros das comunidades escolares.

Uma cronologia da sociologia da educação, ao longo do século $\mathrm{XX}$, anotaria o destaque para aspectos que podem ser chamados de "pequena escala" especialmente a partir da virada dos anos 70 para os 80 . Nesse sentido, temáticas como as estratégias familiares tenderam a ganhar relevância, em certo contraponto a abordagens mais macro, que relacionavam classes ou grupos étnicos com variáveis educacionais. Há, porém, que ressaltar a coexistência, desde a fundação da sociologia da educação contemporânea - nos anos 1950 -, entre essas distintas formas de abordagem, lembrando, ainda que, desde sua origem recente, a sociologia da educação sempre reservou lugar de relevo ao tema da família. No caso do Brasil, essa parece mesmo ser a temática predominante no ambiente da sociologia da educação dos últimos anos (COSTA; SILVA, 2003).

Por seu turno, a questão das hierarquias escolares é um tema ainda nebuloso, mesmo que tenha tomado grande impulso com o desenvolvimento de estudos sobre eficácia escolar e efeito escola, os quais colocam em evidência a diferenciação entre estabelecimentos, dado que procuram aferir seus efeitos controlando as características particulares de suas clientelas.

O presente artigo concentrará seus esforços na problemática brasileira. A literatura internacional é considerada e ajudou a formular questões 
relevantes para a pesquisa. Todavia, aquilo que pretendemos denominar hierarquias escolares é algo bastante diverso, por exemplo, de países em que estratégias de criação/estímulo ao quase-mercado educacional foram desenvolvidas.

Quando tratamos de hierarquias escolares não estamos, contudo, presos ao referencial que procura medi-las fundamentalmente a partir de seus resultados em avaliações de aprendizado. De forma alguma renegamos a importância vital de tais trabalhos. Eles são, de fato, pilar fundamental do que pretendemos desenvolver. Há, porém, que reconhecer que a hierarquia entre as escolas ou intraescolar é um fenômeno complexo, para além do desempenho dos estudantes, ainda que guarde relação com tal aspecto. Sensos de superioridade e inferioridade estão presentes no cotidiano da vida social, entre grupos sociais e indivíduos, e permeiam o sistema escolar. Nosso interesse é auxiliar sua compreensão, no que respeita suas manifestações no âmbito escolar, mas também tomando o sistema escolar como caixa de ressonância para as hierarquias sociais.

Um dos aspectos centrais, sob esse ângulo, está na seleção de acesso às escolas, que ocorre em conjugação de ação familiar com seletividade ativa das escolas, mediada por elementos culturais que, de certa forma, também podem ser associados a recursos tipicamente familiares.

Usualmente, o mecanismo mais simples de hierarquização de escolas se baseia no ranqueamento de estabelecimentos, tomando como referência desempenhos em iniciativas de avaliação externa. Empresas educacionais adotam taxas de aprovação em seleções de universidades prestigiadas, especialmente como recurso de marketing. Tais procedimentos tendem a destacar o contraste entre redes distintas de ensino (pública $\mathrm{X}$ privada) e/ou entre escolas (algumas de nível federal) que se destacam persistentemente no topo das escalas produzidas. Alguns estudos têm se dedicado a traçar detidamente os perfis de tais estabelecimentos de topo e de seus frequentadores (BRANDÃO 2006a; 2006b; 2005; ALMEIDA 2002; NOGUEIRA 1998a; 1998b; 1999; 2002; 2004).

Procuramos dialogar com tais linhas de investigação, mas buscamos focar nossa atenção em outro ambiente educacional, que não frequenta páginas de jornal, exceto quando de denúncias sobre as incontáveis mazelas das redes públicas de ensino de massas. Há, porém, também em meio às multidões de matriculados em tais estabelecimentos, forte senso de hierarquia, disputas acirradas por locais mais prestigiados e, sobretudo, percepções de que diante de uma oferta escolar, via de regra, 
sofrível, as oportunidades futuras estão fortemente condicionadas pelo resultado do jogo de obtenção de vagas, em um processo claramente cumulativo. Os circuitos virtuosos e viciosos, para os que dependem de uma oferta educacional reconhecidamente precária, por não disporem de recursos para aceder escolas realmente prestigiosas, parecem começar ainda muito cedo, nos primeiros momentos de ingresso na escola.

$\mathrm{Na}$ rede municipal cujos casos estudamos, diversos depoimentos indicam haver caminhos especiais construídos entre escolas de educação infantil até aquelas que se ocupam das séries iniciais do ensino fundamental, com sequência pelas séries finais desse nível e, curiosamente, estendendo sua trajetória pela rede estadual, responsável pelo ensino secundário. Esquematicamente, um aluno que entre em determinada escola pública, destacada por seu alto prestígio em seu ambiente social, aumenta consideravelmente suas chances de percorrer um circuito subsequente de escolas igualmente prestigiosas e, obviamente, mais disputadas. O percurso oposto também parece realidade. É provável que, em um meio termo, se alinhem escolas e estudantes que embaralham um pouco o modelo dicotômico aqui adotado. Podemos pensar nas escolas públicas de redes amplas como ocupantes de posições em uma escala de prestígio e disputa - equivalente, mas não coincidente, às posições tomadas nas escalas de proficiência acadêmica.

São bastante nebulosos os mecanismos pelos quais a seleção de acesso a tais estabelecimentos destacados se dá. São mesmo segredo bemguardado, ao qual a burocracia educacional só se refere em off. O desafio enfrentado por essa abordagem da pesquisa é, portanto, observar características do alunado de escolas públicas díspares, tentando identificar fatores associados à presença em um tipo de escola. Encontramos, porém, para além das características do alunado, evidências do papel ativo dos estabelecimentos escolares na diferenciação entre alunos e, por conseguinte, na definição de suas chances escolares.

Ao forçarmos a adoção de um modelo dicotômico, com escolas de prestígio bem distinto, deparamo-nos com ambientes educacionais muito diferentes, mas também fortemente segmentados internamente, indicando que as hierarquias não estão apenas entre os estabelecimentos, mas também intraestabelecimentos.

O alunado reconhece e reage a tal sistema classificatório de forma adaptativa e reativa, formando atitudes, percepções e estratégias detectáveis sob diversas formas nas coletas de dados efetuadas. 
Apresentaremos, a seguir, resultados que evidenciam essa diferenciação para, na sequência, tentarmos modelos explicativos das probabilidades de estar em escolas e turmas consideradas de alto prestígio por gestores, professores, pais e alunos. Nos modelos, será destacado o peso da composição familiar.

O survey com estudantes (todos os presentes) nas seis escolas que compõem nosso universo de estudo foi aplicado ao final do segundo semestre de 2006, de forma orquestrada, turma a turma. Os estudantes de $5^{a}$ a $8^{a}$ séries recebiam um questionário com 55 perguntas, desdobradas em cerca de 200 itens no banco de dados, versando sobre diversos aspectos de sua vida escolar pregressa: a composição da família; suas características demográficas gerais; hábitos e práticas cotidianos; percepções e expectativas; seu meio de convivência; e, por fim, inúmeros aspectos de sua escola atual, envolvendo as avaliações detalhadas, os padrões de relacionamento com os diversos integrantes desse ambiente, seus sentimentos quanto à presença e o pertencimento à escola em que se encontram. Para apresentação de resultados, optamos por expor descritivamente ${ }^{4}$ alguns elementos que serão relevantes na tentativa de compor os modelos preditivos desenhados ao final, formando um quadro de marcantes diferenças entre escolas e turmas.

Os dados serão organizados por escola, tendo sido adotada denominação para essas que indicam a área de cidade em que se encontram, acrescida de um sinal + ou - indicando o prestígio relativo da escola, na comparação com sua correspondente geográfica. Assim, são duas escolas para cada zona da cidade (Norte, Sul e Tijuca e Adjacências), com prestígio positivo ou negativo. Dessa forma, quando nos referirmos à escola $\mathrm{T}+$, estaremos tratando da escola considerada de alto prestígio situada na Tijuca. Da mesma forma, a escola N- é aquela situada na Zona Norte, gozando de baixo prestígio. Há forte distinção socioeconômica entre essas áreas, conforme fica evidente nos dados. A essa desigualdade somam-se profundas diferenças quanto a acesso a serviços públicos, bens culturais, etc. No caso da pesquisa, a região mais pobre e mais desprovida de bens e serviços é a Zona Norte, seguida da Tijuca e adjacências, e, na série, da Zona Sul - a região economicamente mais afluente da cidade. 
Por conta da incomum organização espacial da cidade, em todas as regiões convivem favelas com áreas urbanas mais consolidadas. Assim, podemos dizer que todas as escolas de nossa "amostra" contam com alunos residentes em favelas e áreas bastante degradadas. Porém, mesmo entre essas favelas e ocupações irregulares, há clara diferenciação quanto aos padrões de vida, conforme nos distanciamos das áreas mais ricas ou do centro econômico financeiro do Rio de Janeiro. Não efetuamos a pesquisa - por limitação de recursos - em áreas ainda mais afastadas e pobres da cidade, como os rincões da Zona Oeste ou áreas ainda mais pobres da Zona Norte. Sempre que possível, os resultados serão apresentados em forma gráfica, para facilitar a percepção dos contrastes.

Como ponto de partida são expostas as diferenças de nível socioeconômico e de escolaridade da mãe, informando diferenças "duras", diretamente indicativas de padrões de vida e posições econômicas desfrutadas. Pode-se considerar, como usual, em acréscimo, a escolaridade da mãe um indicador importante do capital cultural disponível familiarmente. O nível socioeconômico foi construído com as informações sobre a posse de bens domésticos, devidamente ponderados quanto à sua escassez relativa, somados e padronizados. A escolaridade da mãe foi escolhida, em detrimento de uma medida mais rica que a compusesse com a escolaridade do pai, em função do alto nível de ausência de informações sobre os pais, especialmente conforme se desce na estratificação social, além do reconhecimento quanto a seu papel primordial na integração dos filhos à vida escolar.

\section{Gráfico 1}

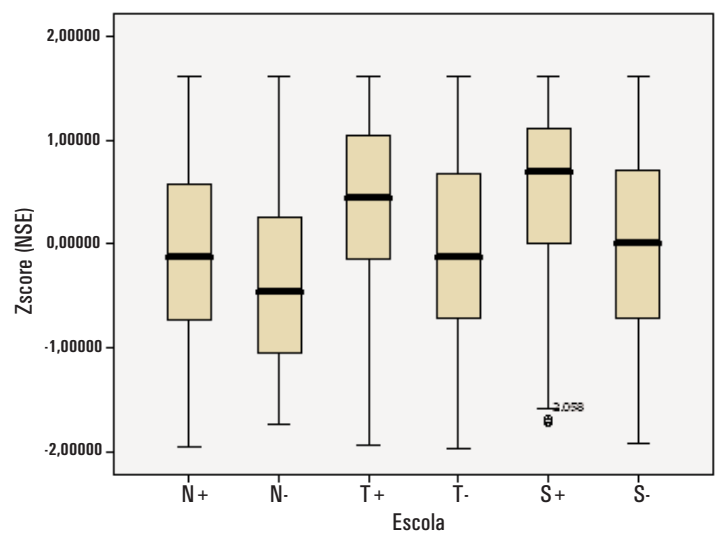

Educação em Revista | Belo Horizonte | v.26 | n.02 | p.227-248 | ago. 2010 
Como se pode observar, os contrastes são nítidos em dois sentidos: regional e entre as escolas de cada área. É interessante mencionar que, entre as escolas da Zona Norte, a N+ está localizada em região mais pobre e mais degradada, mais assolada por problemas de violência urbana do que sua correspondente de baixo prestígio. Já na Tijuca, as escolas ficam muito próximas entre si, em área tipicamente de classe média. $\mathrm{Na}$ Zona Sul, a escola S+ está situada em área muito valorizada territorialmente, sem favelas próximas, mas a $\mathrm{S}$ - também se localiza em região de destaque, ainda que menor, dispondo de grande facilidade de meios de acesso. Assim, as diferenças de NSE entre as escolas da mesma região não podem ser explicadas por características do espaço geográfico em que estão inseridas. Há ainda o fenômeno, registrado em entrevistas com as direções das escolas, de que aquelas de alto prestígio tendem a atrair alunos de áreas distantes de seu entorno, ao passo que as de baixo prestígio são frequentadas quase exclusivamente por alunos das redondezas (fato verificado indiretamente no survey de alunos, como se verá adiante). Seguindo a distribuição regional da riqueza, o nível socioeconômico mediano medido na escola $\mathrm{N}+$ é ainda inferior ao da S-. As diferenças são perceptíveis também na observação direta, frequente, nas escolas. Vestimentas e cor da pele reforçam a impressão de desníveis sociais relevantes, ainda que talvez pouco perceptíveis em um contraste com alunos, por exemplo, da rede privada ou federal.

\section{Gráfico 2}

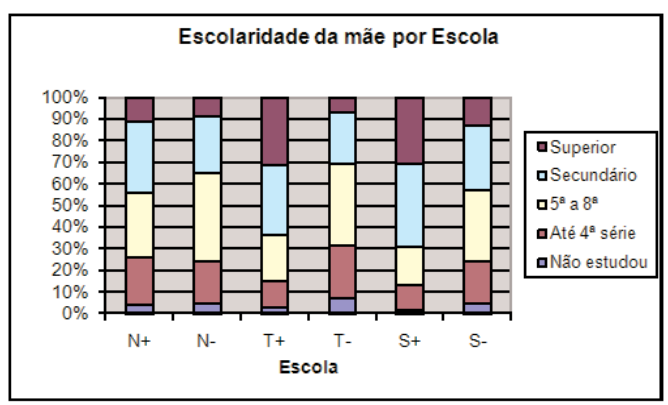

A escolaridade das mães segue o padrão esperado e associado ao nível socioeconômico, com comportamento um tanto anômalo apenas na escola $\mathrm{N}+$, que se aproxima mais do padrão da escola $\mathrm{N}^{-}{ }^{5}$. No entanto, a 
regra é uma grande distância, principalmente no nível superior, entre as escolas dos dois tipos.

A autodeclaração de cor permitiu que criássemos uma variável dicotômica Brancos/Orientais e Outras Cores. O resultado de sua tabulação ${ }^{6}$ por escola é condizente com nossa observação in loco. Há evidente maior parcela de alunos que se declaram brancos (ou orientais, em proporção muito reduzida) nas escolas de alto prestígio, assim como na Zona Norte é substantivamente mais baixa a proporção dos que assim se declaram. Podemos tomar esse indicador como evidência de diferenciação socioeconômica, mas não pudemos deixar de considerar a possibilidade de ocorrência de algum tipo de segregação no acesso e na permanência nas escolas mais procuradas, associada à cor da pele. Posteriormente, testamos essa possibilidade em modelo multivariado e ela não se sustentou?.

Ainda explorando aspectos das características mais "estruturais", criamos variáveis para medir as distâncias dos alunos com relação à idade média dos demais. Assim, podemos perceber como a trajetória escolar incorporada aos alunos, na forma de anos despendidos para alcançar a série em que se encontram, se expressa nas diferentes escolas.

\section{Gráfico 3}

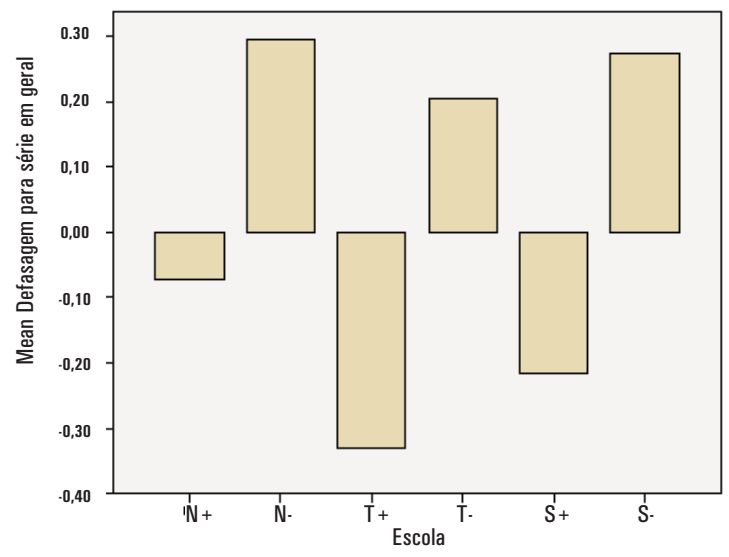

As escolas de alto prestígio estão sempre com seus alunos com "defasagem negativa", ou seja, adiantados relativamente à média do conjunto. Esse quadro não é totalmente gerado no interior dessas escolas de segundo segmento. De fato, já vem se construindo desde o início da esco- 
larização dos alunos, como sugerem os dados sobre a idade de início da escolarização ou de ingresso na $5^{\text {a }}$ série, também em termos médios por escola, expressos nos Gráficos 4 e 5. Diferenças socioeconômicas, vantagens relativas no acesso à escolarização e padrões culturais parecem boas pistas para compreender o fenômeno.

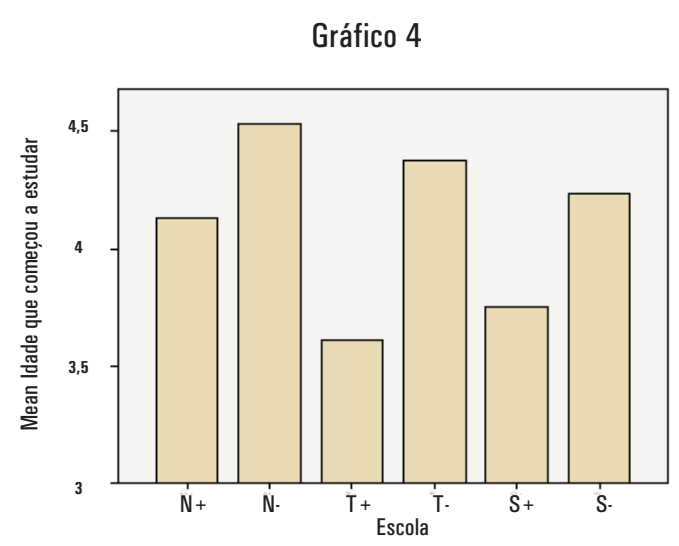

Gráfico 5

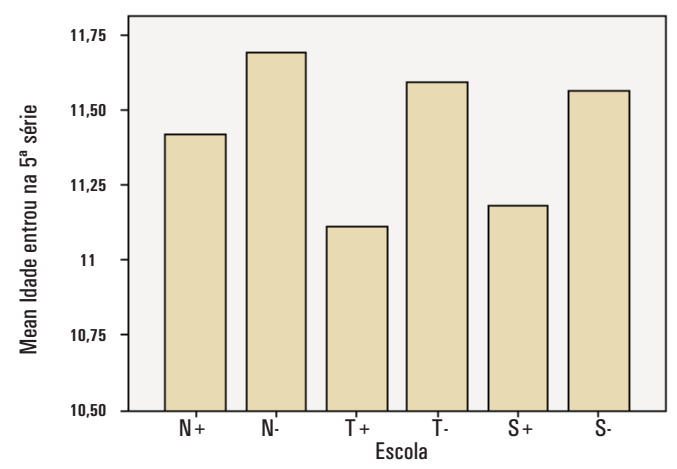

Adentramos, em seguida, no terreno das diferenças culturais entre os públicos das escolas, considerando que devem aí residir boa parte das explicações para as reputações das escolas, sua autoimagem e, sobretudo, das probabilidades de alistamento em uma escola mais ou menos prestigiada, seguindo os influxos das teorias sociológicas "culturalistas", desde os anos 1950. 
Parece-nos que é difícil dissociar as características culturais dos alunos, especialmente ainda bem jovens, daquelas de suas famílias. Consideramos de certa forma alguns traços destacados nesta pesquisa, para os alunos, como prováveis proxy das de suas famílias.

Começamos por uma variável ainda fortemente ancorada nas diferenças socioeconômicas e de capital cultural anteriores. Criamos uma variável para medir, sob formas muito diversas, os acessos dos alunos a meios de informação (jornais, revistas, TV, internet, etc.), resultando em uma variável padronizada que dá uma ideia da existência de diferenças também nesse plano entre as escolas ${ }^{8}$.

\section{Gráfico 6}

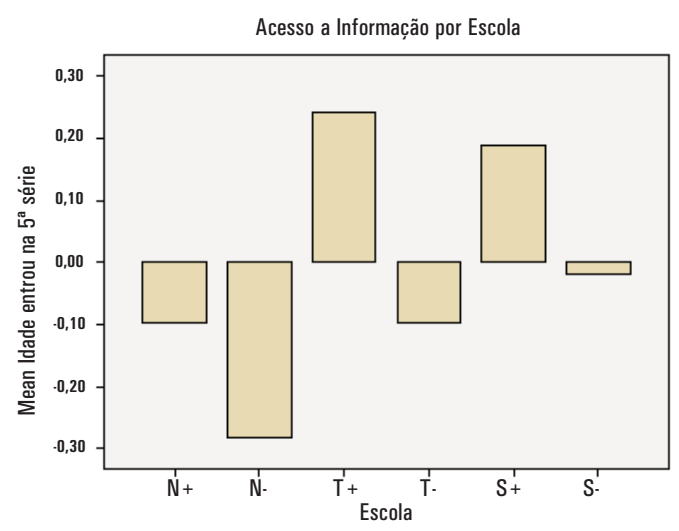

Damos continuidade com uma característica que nos surpreendeu, mas cuja força parece irrecusável, especialmente conforme resistiu a controles pesados nas análises multivariadas.

Tabela 1

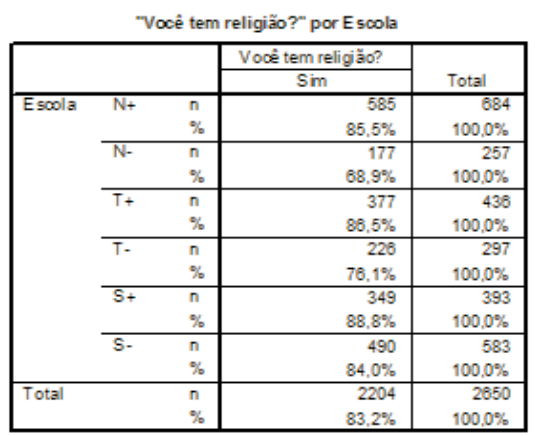

Educação em Revista | Belo Horizonte | v.26 | n.02 | p.227-248 | ago. 2010 
O índice de declaração de religiosidade cresce lentamente da Zona Norte para a Zona Sul, entre as escolas de alto prestígio. Dá saltos mais consideráveis nas de baixo prestígio, mas apresenta sempre distinção estatisticamente significativa entre os alunos das escolas de alto e baixo prestígio. Esse é um fenômeno a ser compreendido à luz de uma necessária conjunção entre sociologia da educação e da religião - conjunção que inacreditavelmente não existe com a força merecida. Quais seriam as hipóteses para explicar esse resultado?

Um indicador que parece pertinente do tipo de relações sociais mantidas pelos alunos fora de sua escola, mas também no ambiente escolar, está expresso no quadro a seguir, que exprime as respostas para a pergunta sobre amigos que pararam de estudar.

Tabela 2

\begin{tabular}{|c|c|c|c|c|c|c|c|c|}
\hline & & & \multicolumn{5}{|c|}{ Há a migos ou colegas que parara m de estudar? } & \multirow[b]{2}{*}{ Total } \\
\hline & & & Nenhum & $\begin{array}{l}\text { Quase } \\
\text { nenhum }\end{array}$ & Poucos & Simalguns & Sim, muitos & \\
\hline \multirow[t]{12}{*}{ Escola } & \multirow[t]{2}{*}{$\mathrm{N}+$} & $\mathrm{n}$ & 257 & 103 & 115 & 107 & 97 & 879 \\
\hline & & $\%$ & $37,8 \%$ & $15.2 \%$ & $16,9 \%$ & $15,8 \%$ & $14,3 \%$ & $100,0 \%$ \\
\hline & \multirow[t]{2}{*}{$\mathrm{N}$} & $\mathrm{n}$ & 74 & 38 & 48 & 50 & 43 & 251 \\
\hline & & $\%$ & $29,5 \%$ & $14,3 \%$ & $19,1 \%$ & $19,9 \%$ & $17,1 \%$ & $100,0 \%$ \\
\hline & \multirow[t]{2}{*}{$\mathrm{T}+$} & $\mathrm{n}$ & 240 & 76 & 48 & 43 & 24 & 431 \\
\hline & & $\%$ & $55,7 \%$ & $17,6 \%$ & $11,1 \%$ & $10,0 \%$ & $5,6 \%$ & $100,0 \%$ \\
\hline & \multirow[t]{2}{*}{ T. } & $\mathrm{n}$ & 82 & 53 & 63 & 64 & 28 & 290 \\
\hline & & $\%$ & $28,3 \%$ & $18,3 \%$ & $21,7 \%$ & $22,1 \%$ & $9,7 \%$ & $100,0 \%$ \\
\hline & \multirow[t]{2}{*}{$\mathrm{S}+$} & $\mathrm{n}$ & 197 & 58 & 62 & 59 & 15 & 391 \\
\hline & & $\%$ & $50,4 \%$ & $14,8 \%$ & $15,9 \%$ & $15,1 \%$ & $3,8 \%$ & $100,0 \%$ \\
\hline & \multirow[t]{2}{*}{ S- } & $\mathrm{n}$ & 185 & 73 & 113 & 113 & 87 & 571 \\
\hline & & $\%$ & $32,4 \%$ & $12,8 \%$ & $19,8 \%$ & $19,8 \%$ & $15,2 \%$ & $100,0 \%$ \\
\hline \multirow[t]{2}{*}{ Total } & & $\mathrm{n}$ & 1035 & 399 & 449 & 436 & 294 & 2813 \\
\hline & & $\%$ & $39,6 \%$ & $15,3 \%$ & $17,2 \%$ & $16,7 \%$ & $11,3 \%$ & $100,0 \%$ \\
\hline
\end{tabular}

Interpretamos as respostas a esse item como um indicativo do tipo de convívio social dos alunos. As diferenças são, mais uma vez, marcantes. As hierarquias geográficas e interescolares se manifestam. Destacamos esse resultado por conta de ser expressivo também nas análises multivariadas.

Chegamos ao ponto em que a estrutura familiar, ainda que desenhada de forma singela, pode auxiliar a compreensão do que pretendemos. Há dois indicativos destacados para esse aspecto, profundamente inter-relacionados: aquilo que denominamos "Tipo de família", quanto à presença dos pais residindo com o aluno; e a responsabilidade pela manutenção do espaço doméstico. 
Tabela 3

\begin{tabular}{|c|c|c|c|c|c|c|c|}
\hline \multicolumn{8}{|c|}{ Tipo de familia por Escola } \\
\hline & & & \multicolumn{4}{|c|}{ Tipo de fanília } & \multirow[b]{2}{*}{ Total } \\
\hline & & & $\begin{array}{c}\text { Família } \\
\text { biparental }\end{array}$ & $\begin{array}{c}\text { Familia } \\
\text { monoparental }\end{array}$ & $\begin{array}{c}\text { Família com } \\
\text { padrasto/nz } \\
\text { drasta }\end{array}$ & $\begin{array}{l}\text { Outros tipos } \\
\text { de familia }\end{array}$ & \\
\hline \multirow[t]{12}{*}{ Escola } & \multirow[t]{2}{*}{$\mathrm{Nt}$} & $\mathrm{n}$ & 408 & 170 & 77 & 31 & 684 \\
\hline & & $\%$ & $59,4 \%$ & $24,9 \%$ & $11,3 \%$ & $4,5 \%$ & $100,0 \%$ \\
\hline & \multirow[t]{2}{*}{$\mathrm{N}$} & $\mathrm{n}$ & 124 & 74 & 37 & 22 & 257 \\
\hline & & $\%$ & $48,2 \%$ & $28,8 \%$ & $14,4 \%$ & $8,6 \%$ & $100,0 \%$ \\
\hline & \multirow[t]{2}{*}{$\overline{T+}$} & $\mathrm{n}$ & 271 & 113 & 35 & 17 & 436 \\
\hline & & $\%$ & $62,2 \%$ & $25,9 \%$ & $8,0 \%$ & $3,9 \%$ & $100,0 \%$ \\
\hline & \multirow[t]{2}{*}{ T- } & $\mathrm{n}$ & 169 & 80 & 32 & 18 & 297 \\
\hline & & $\%$ & $56,9 \%$ & $28,9 \%$ & $10,8 \%$ & $5,4 \%$ & $100,0 \%$ \\
\hline & \multirow[t]{2}{*}{$\mathrm{S}+$} & $\mathrm{n}$ & 223 & 115 & 34 & 21 & 398 \\
\hline & & $\%$ & $56,7 \%$ & $29,3 \%$ & $8,7 \%$ & $5,3 \%$ & $100,0 \%$ \\
\hline & \multirow[t]{2}{*}{ S- } & $\mathrm{n}$ & 259 & 178 & 99 & 49 & 583 \\
\hline & & $\%$ & $44,4 \%$ & $30,2 \%$ & $17,0 \%$ & $8,4 \%$ & $100,0 \%$ \\
\hline \multirow[t]{2}{*}{ Total } & & $\mathrm{n}$ & 1452 & 728 & 314 & 158 & 2650 \\
\hline & & $\%$ & $54,8 \%$ & $27,5 \%$ & $11,8 \%$ & $5.9 \%$ & $100,0 \%$ \\
\hline
\end{tabular}

Tabela 4

\begin{tabular}{|c|c|c|c|c|c|c|c|}
\hline \multicolumn{8}{|c|}{ Principal re sponsável pelo sustento da casa por Escola } \\
\hline & & & \multicolumn{4}{|c|}{ Principal responsável pelo sustento da casa } & \multirow[b]{2}{*}{ Total } \\
\hline & & & Paie măe & Pai & Mằ & Outros & \\
\hline \multirow[t]{12}{*}{ Escola } & $\mathrm{N}_{+}^{+}$ & $\mathrm{n}$ & 250 & 173 & 205 & 56 & 684 \\
\hline & & $\%$ & $36,5 \%$ & $25,3 \%$ & $30,0 \%$ & $8,2 \%$ & $100,0 \%$ \\
\hline & $\mathrm{N}$ & n & 74 & 65 & 93 & 25 & 257 \\
\hline & & $\%$ & $28,8 \%$ & $25,3 \%$ & $36,2 \%$ & $9,7 \%$ & $100,0 \%$ \\
\hline & $T_{+}$ & n & 173 & 109 & 117 & 37 & 438 \\
\hline & & $\%$ & $39,7 \%$ & $25,0 \%$ & $26,8 \%$ & $8,5 \%$ & $100,0 \%$ \\
\hline & T- & n & 109 & 70 & 94 & 24 & 297 \\
\hline & & $\%$ & $36,7 \%$ & $23,6 \%$ & $31,6 \%$ & $8,1 \%$ & $100,0 \%$ \\
\hline & S+ & $\mathrm{n}$ & 138 & 103 & 121 & 33 & 393 \\
\hline & & $\%$ & $34,6 \%$ & $26,2 \%$ & $30,8 \%$ & $8,4 \%$ & $100,0 \%$ \\
\hline & S- & $\mathrm{n}$ & 179 & 101 & 230 & 73 & 583 \\
\hline & & $\%$ & $30,7 \%$ & $17,3 \%$ & $39,5 \%$ & $12,5 \%$ & $100,0 \%$ \\
\hline \multirow[t]{2}{*}{ Total } & & $\mathrm{n}$ & 921 & 621 & 860 & 248 & 2850 \\
\hline & & $\%$ & $34,8 \%$ & $23,4 \%$ & $32,5 \%$ & $9.4 \%$ & $100,0 \%$ \\
\hline
\end{tabular}

O percentual mais elevado de famílias biparentais nas escolas de alto prestígio se manifesta também no maior índice de domicílios com sustentação principal por pai e mãe. Por outro lado, um reconhecido indicador de condições materiais mais precárias - a principal sustentação provir da mãe - se apresenta nas escolas de menos prestígio. Uma hipótese plausível seria que a base socioeconômica mais afluente das famílias biparentais seria o verdadeiro fator que asseguraria a presença dos alunos nas escolas mais prestigiosas. Há, porém, a possibilidade de que componentes propriamente da estrutura familiar, a suposta maior estabilidade dessas famílias, entraria como um componente para além das vantagens econômicas. Tavares Jr. (2007), reportando a Biblarz (1999), relata efeito semelhante, com as "estruturas familiares alternativas" resultando em desvantagens escolares persistentes nos filhos de famílias single, nos Estados Unidos. Essas hipóteses serão testadas. 
Há diversas outras diferenças relevantes, sob outros ângulos, culturais, de acesso a lazer, de hábitos e práticas, diferenças de gênero, de expectativas futuras, de inúmeros aspectos de avaliação das escolas e dos relacionamentos com seus integrantes. Enfim, o survey e as observações e entrevistas resultaram em imagens bastante distintas dessas escolas, referendando a noção de que há universos escolares em muito diferentes, em escolas submetidas às mesmas regras e autoridade, dispondo de recursos equivalentes, sobre as mesmas bases geográficas.

Os motivos de escolha das escolas - ou as justificativas para presença nelas - variam enormemente. Nas escolas de alto prestígio, a qualidade e a recomendação de conhecidos são os fatores destacados. Nas escolas de baixo prestígio, a proximidade da residência aparece como motivo principal. A autoimagem como aluno, também diferindo significativamente entre as escolas, pode ser resultado da socialização em ambientes de orgulho grupal desenvolvido - como na Winston Parva, de Elias/

Scotson, mas também pode indicar uma atitude de maior "empreendedorismo escolar", de mais elevadas expectativas e cobranças (por que não familiares), que redundam em trajetórias escolares virtuosas.

De forma a avaliar o impacto das variáveis associadas com a dimensão familiar dos alunos na chance de presença em uma escola de alto ou baixo prestígio, aplicamos regressão logística em modelo de passos sucessivos. Apresentamos, a seguir, os resultados da regressão, concentrando atenção nas variáveis associadas à dimensão família, secundados pelo quadro de classificação de resultados previstos corretamente.

Tabela 5

\begin{tabular}{|c|c|c|c|c|c|}
\hline \multicolumn{6}{|c|}{ Regressão logística para chance de estar em escola de alto prestígio } \\
\hline & \multicolumn{5}{|c|}{ Modelo } \\
\hline & 1 & 2 & 3 & 4 & 5 \\
\hline NSE $(Z)$ & $1,33^{* *}$ & $1,29^{*}$ & $1,26^{*+}$ & $1,26^{-}$ & $1,28-$ \\
\hline Es colaridade da mãe & $1,30^{*}$ & $1,31^{\cdots}$ & $1,33^{*}$ & $1,30^{-}$ & $1,28-$ \\
\hline Idade entrou 5 a série & & $0,77^{\infty \times}$ & $0,79^{\infty}$ & $0.83^{-}$ & $0,82^{-m}-(-1-1+1$ \\
\hline $\begin{array}{l}\text { Temreligiäo } \\
\text { Tipo de familia }\end{array}$ & & & $1,49^{*}$ & $1,42^{-}$ & $1,34^{*}$ \\
\hline Biparental & & & $1,84^{* *}$ & $1.83^{-}$ & $1.81^{-}$ \\
\hline Monoperental & & & $1,42^{*}$ & $1,44^{*}$ & 1,29 \\
\hline Compadras to/madr as ta & & & 1,02 & 1,05 & 1,00 \\
\hline Coleges pararamde estudar & & & & $0,85^{-}$ & $0,88^{-}$ \\
\hline Auto imagem como aluno & & & & & $1,15^{*}$ \\
\hline Motivo: proximidade & & & & & $0,51^{-}$ \\
\hline Motivo: indicaçẫo & & & & & $1,98-$ \\
\hline Motivo: qualidade & & & & & $5,06^{-}$ \\
\hline Constant & 0,47 & 11,14 & 3,57 & 3,15 & 1,30 \\
\hline \multicolumn{6}{|c|}{$\begin{array}{l}\text { Variável dependente: Prestgio da escola (alto ou baixo). } \\
\text { NSE : Nivel sociceconómico (escala ponderada e padronizada de posse de bens domésticos) }\end{array}$} \\
\hline \multicolumn{6}{|c|}{$\begin{array}{l}\text { Escolaridade da măe: ordinal } 1 \text { a } 5 \text { (sem estudo a nivel superior) } \\
\text { Tem religiäo: dicotômica }\end{array}$} \\
\hline \multicolumn{6}{|c|}{ Tipo de familia: categoria de base é "outros tipos". } \\
\hline \multicolumn{6}{|c|}{ Colegas/amigos pararam de estudar: ordinal (1 - renhum a 5 - muitos) } \\
\hline \multicolumn{6}{|c|}{$\begin{array}{l}\text { Auto imagem como aluno: ordinal ( } 1 \text { - muito ruim a } 5 \text { - muito bom) } \\
\text { Idade entrou para 5a série: em anos inteiros }\end{array}$} \\
\hline Motivos: para escolha da escola & & & & & \\
\hline
\end{tabular}

Educação em Revista | Belo Horizonte | v.26 | n.02 | p.227-248 | ago. 2010 
Conforme esperado, variáveis estruturais, indicativas de condições de vida e do acesso a bens públicos, funcionaram estavelmente nos modelos. Assim, a escolaridade da mãe e o nível socioeconômico domiciliar jogam papel relevante na definição do prestígio da escola em que o aluno estava no momento da pesquisa. Da mesma forma, a idade de ingresso na $5^{a}$ série reduz consideravelmente (quase $20 \%$ por ano a mais) as chances de se estar em uma escola considerada de alto prestígio. Nesse ponto começam a estar imbricadas vantagens e constrangimentos do meio de origem, mas também devem operar elementos da vida escolar dos alunos, à medida que atrasos, abandonos e reprovações são cristalizados na idade de frequência às séries. Deve-se destacar que o coeficiente elevado para diferenças de ingresso na $5^{\text {a }}$ série, segundo o tipo de escola, já revela a operação de mecanismos de seleção de acesso pelas escolas.

Num segundo bloco de variáveis, religião e tipo de família (quanto à presença materna e paterna) podem ser considerados fatores estritamente familiares, enquanto a religião pode ser tratada, na faixa etária desses alunos, como variável também familiar. $\mathrm{O}$ elevado coeficiente obtido pela declaração de professar alguma religião sugere uma vasta e pouco explorada área de investigação para a sociologia da educação. Por que razões a religião, controlados os demais fatores, permanece significativamente aumentando as chances de presença em escola prestigiosa? Algo no nível da autodisciplina? Da heterodisciplina? Esquemas ascéticos? Não dispomos de elementos nessa pesquisa para ir além da especulação, mas reafirmamos a importância vital de compreender, no âmbito da sociologia da educação, as relações entre religiosidade - dimensão fundamental na compreensão dos comportamentos e escolhas humanas - e fenômenos educacionais, inclusive no que respeita a diferentes credos.

Já o alto coeficiente da variável "família biparental" descortina outro amplo campo de estudo. Em todos os modelos, integrar uma família biparental quase dobra as chances do aluno. Considerando o controle por um indicador de capital cultural (escolaridade da mãe) e por outras variáveis culturais e contextuais fortes (círculo de convivência além da família; autoimagem; motivos de escolha da escola; NSE), a força dessa variável sugere estudar a relação família/escola talvez para além das abordagens sobre o capital cultural e as estratégias familiares.

Por fim, a força dos coeficientes que congregam os motivos declarados para escolha da escola traz a particularidade de destacar as pos- 
sibilidades seletivas disponíveis às escolas de maior prestígio. A escolha pela qualidade ${ }^{9}$ da escola quintuplica as chances de os alunos estarem em escola prestigiosa, enquanto a escolha por critério de proximidade da residência reduz à metade essa probabilidade.

Nosso trabalho qualitativo revelou ser comum a situação de alunos que percorrem trechos razoavelmente longos para frequentar as escolas mais prestigiadas. Da mesma forma, tivemos notícias de alunos que, diante da escolha por proximidade resultar em escola considerada ruim, optam por buscar alternativas distantes. Temos também relatos de como é difícil obter vagas nessas escolas e como abundam vagas não ocupadas nas escolas de baixo prestígio, o que remete, mais uma vez, ao tema da família, dado que a batalha por vagas, no caso do Rio de Janeiro, praticamente inexiste, mas sim a por vagas de qualidade.

Concluindo essa apresentação de resultados, aplicamos outro modelo de regressão logística para estimar a força relativa de algumas variáveis na predição das chances de alunos estarem inscritos em turmas consideradas melhores. Como é sabido, é comum que as escolas apresentem fortes hierarquias internas, no agrupamento de alunos em turmas (ALVES, 2007). Nas redes públicas, o princípio fundamental de hierarquização é a idade dos alunos - especialmente conforme as séries avançam. Frequentemente, a numeração identificadora da turma indica sua posição relativa diante de uma escala de prestígio interno nas escolas. As turmas "01" são habitualmente aquelas consideradas "fortes", boas, contando com alunos que dispõem de vantagens relativas e, sobretudo, mais jovens. O próprio princípio do agrupamento por idade, usual na organização por ciclos, consagra essa hierarquia de prestígio, que parece existir desde longo tempo.

Assim, resolvemos testar hipóteses de condições causais para a presença em uma turma prestigiada. Para isso, aplicamos uma regra simples de dividir dicotomicamente as turmas usando a média de idade geral observada em cada série. Esse procedimento, ainda que acarrete algumas imprecisões ${ }^{10}$, mostrou-se interessante, permitindo uma previsão correta em quase $80 \%$ dos casos. 
Tabela 6

\begin{tabular}{|c|c|c|c|c|c|}
\hline \multicolumn{6}{|c|}{ Regres são logística para chance de estar em turma de baixa média de id ade } \\
\hline & \multicolumn{5}{|c|}{ Modelo } \\
\hline & 1 & 2 & 3 & 4 & 5 \\
\hline NSE (Z) & $1,25^{-}$ & 1,11 & 1,09 & 1,03 & 1,04 \\
\hline Escolaridade da mãe & $1,43^{-}$ & $1,27^{-}$ & $1,29^{*}$ & $1,23^{\text {** }}$ & $1.22^{\circ}$ \\
\hline Prestígio da es cola & & $3.85^{-}$ & $3,71^{*-}$ & $3,46^{+*}$ & $6,74^{*}$ \\
\hline Idade começou a estudar & & $0,80^{-}$ & $0,80^{* *}$ & $0,82^{-}$ & $0,84^{*}$ \\
\hline \multicolumn{6}{|l|}{ Tipo de família } \\
\hline Biperental & & & $1,92^{*}$ & $1,92^{* *}$ & 1,39 \\
\hline Monparental & & & 1,38 & 1,39 & 1,20 \\
\hline Com padrasto/madrasta & & & 1.12 & 1,20 & 1,05 \\
\hline Colegas pararam estudar? & & & & $0,68^{* *}$ & $0,71^{\star *}$ \\
\hline Acesso a informação $(Z)$ & & & & $1,21^{\infty}$ & $1,20^{\text {* }}$ \\
\hline Turno (tarde) & & & & & $0.09^{\circ}$ \\
\hline Constant & 0,54 & 1,02 & 0,64 & 1,90 & 58,32 \\
\hline \multicolumn{6}{|c|}{$\begin{array}{ll}\text { Variável dependente: Idade média da turma (alta ou baiva). } & -p<0,001 * p<0,05\end{array}$} \\
\hline \multicolumn{6}{|c|}{ NSE : Nivel socioeconômico (escala ponderada e padronizada de posse de bens domésticos) } \\
\hline \multicolumn{6}{|c|}{ Escolaridade da mãe: ordinal 1 a 5 (sem estudo a ni vel superior) } \\
\hline \multicolumn{6}{|c|}{ Prestigio da escola: 0 - Baixo, 1 - Alto } \\
\hline \multicolumn{6}{|c|}{ Idade $\infty$ mepou a estudar: em anos inteiros } \\
\hline \multicolumn{6}{|c|}{ Tipo de familia: categoria de base é "outros tipos". } \\
\hline \multicolumn{6}{|c|}{ Colegas/amigos pararam de estudar: ordinal (1 - nenhum a 5 - muitos) } \\
\hline \multicolumn{6}{|c|}{$\begin{array}{l}\text { Acesso a informaçăo: escala (padronizada) de acesso a diversos meios de informaçăo } \\
\text { (TV, rádio, computador, computador, jornais, revistas, etc.) }\end{array}$} \\
\hline
\end{tabular}

Considerando a distribuição por turmas, surpreendentemente, o nível socioeconômico não apresentou significância suficiente nos modelos mais complexos, com número maior de variáveis. Poder-se-ia considerar que o NSE opera mais basicamente na definição das chances de estar em uma escola de alto prestígio. Com efeito, a partir do momento em que se introduziu a variável de controle "prestígio da escola" no modelo, o NSE deixou de funcionar. Porém seu coeficiente na regressão anterior (Tabela 5) não é tão elevado assim. Parece que princípios internos à trajetória escolar são de fato os decisivos.

No que interessa ao recorte aqui desenvolvido, é extremamente relevante que o tipo de família continue significativo até o modelo de número 4. Independentemente do padrão de escola, ainda assim as famílias biparentais quase dobram as chances de seus filhos, na pesquisa, estarem em uma turma de média de idade mais baixa. Impressiona, ainda, a força da variável turno, revelando outra faceta - já conhecida por quem trabalha em escola ou que realiza pesquisa in loco - da separação entre alunos e da construção de hierarquias escolares/sociais. Estar no turno da tarde reduz a cerca de $10 \%$ a chance de estar em uma turma com média de idade baixa. Esse achado referenda a percepção que tivemos em todas as escolas de que há, na verdade, duas escolas em cada uma: uma pela manhã e outra à tarde. Isso chegou a ser verbalizado por alunos, professores e direções/coordenações. Um aluno da escola $\mathrm{N}+-$ aquela em que observamos maior preocupação com mecanismos não-segregadores entre alunos e que apresenta maiores níveis de variação interna em praticamen- 
te todos os aspectos - verbalizou, de forma contundente, tal quadro ao interrogar se iríamos, em um dia de visita à escola, permanecer à tarde. A resposta positiva recebeu o seguinte comentário: "Aí é que vocês vão ver o que é ruim. Aqui de tarde só tem favelado". Era um aluno negro, de $5^{\text {a }}$ série, ele mesmo morador de uma área de favela - como a grande maioria na escola.

Esse último resultado remete a discussão para além de nosso foco neste artigo, mas nos permite retomar a questão inicial dos possíveis papéis da composição familiar na produção e na sustentação de hierarquias escolares, dado que parece existir um complexo quase-mercado ${ }^{11}$, mesmo nas redes públicas de ensino de escolas "comuns". As políticas de gestão e organização escolares parecem tender a cristalizar vantagens e desvantagens muito precocemente, conforme a literatura internacional já apontou, por outras vias, nos mecanismos de tracking e de cooling-out. Parece que nossa desigualdade educacional, nos amplos segmentos sociais que dependem das redes públicas, sofre influências diversas, inclusive familiares, mas é principalmente produzida por perversos mecanismos afetos às estratégias organizativas de uma oferta escolar extremamente desigual. A população reconhece isso e ajusta seus comportamentos, procurando se resguardar ou tirar vantagem, quando possível ou quando sabido, partilhando de uma visão de mundo hierárquica, que reduz as possibilidades de ações coletivas na contramão de tais tendências.

A variável "tipo de família", denotando a estrutura familiar, ao mostrar força em modelos multivariados, fortalece a atenção sobre essa dimensão no condicionamento das diferenças de oportunidades escolares.

\section{Notas}

${ }^{1}$ Trabalho realizado a partir de pesquisa financiada pelo CNPQ, por meio do Edital Universal 2005. Agradeço especialmente aos alunos da equipe de pesquisa que, quase todos voluntariamente, contribuíram decisivamente para a realização dessa pesquisa.

${ }^{2}$ Não há testes de acesso ou qualquer outro mecanismo público de triagem e alocação de alunos. No caso das turmas, idade é um critério genérico de agrupamento.

${ }^{3}$ Buscamos informações basicamente sobre a procura das escolas, quando da transição das séries iniciais do ensino fundamental para as séries de seu segundo segmento. Apesar de existentes, enfrentamos barreira intransponível para obtenção dos dados precisos. Assim, tivemos de nos contentar com informações sobre escolas próximas geograficamente, mas com contrastes marcantes nessa demanda. Cremos ter conseguido evidên- 
cias bastante sólidas de que trabalhamos em escolas realmente com prestígio e procura contrapostos.

${ }^{4}$ Por efeito de limitação do número de elementos gráficos no artigo, alguns resultados serão mencionados no texto, mas não apresentados na forma de tabelas ou gráficos.

${ }^{5}$ Esse é um resultado encontrado quanto a diversos indicadores "duros". A própria escola N+ vem sendo objeto de estudo mais detido, dado que apresenta padrões organizativos internos que parecem se afastar do modelo de "escola de elite" cultivado pelas duas outras escolas “+”. Não é possível desenvolver isso aqui, mas há um fascinante objeto de estudo sendo elaborado, acerca de um possível modelo de escola que se aproxima de padrões universalistas e republicanos.

${ }^{6}$ Por razões de espaço, suprimimos essa tabela, optando por apenas mencionar seu resultado.

${ }^{7}$ Não foi incluído o modelo de análise de regressão logística em que essa hipótese foi testada, por força de não ser esse um trabalho dedicado ao tema. Porém, dada a relevância que a questão assume nos debates atuais, consideramos recomendável efetuar inúmeras tentativas de encontrar coeficientes de diferenciação significativos para cor de pele, controlados por variáveis socioeconômicas e culturais, mas não resultou bem-sucedido (o que consideramos um resultado bastante positivo e que contraria algumas tendências em políticas públicas hoje em voga).

${ }^{8}$ Soma de variáveis ordinais em escala de frequência para leituras de diversos tipos, acesso a computadores em locais diversos e práticas como ver TV, ir ao cinema, ao teatro, etc.

${ }^{9}$ Não se deve descartar que é plausível pensar nessa resposta também como um efeito combinado da reputação aprendida da escola e um processo socializador, à medida que os alunos das escolas de alto prestígio veem ser cultivado sistematicamente um orgulho pelo pertencimento a uma escola "especial".

${ }^{10} \mathrm{O}$ uso da média de idade geral para toda a série desloca a linha divisória entre as turmas para cima, quando considerado o número de alunos em turmas de baixa idade média e faz com que as escolas de alto prestígio apresentem proporção maior de turmas com baixa média de idade.

${ }^{11}$ Outro artigo está sendo desenvolvido, especificamente para destacar esse polêmico conceito de quase-mercado na compreensão dos mecanismos seletivos e segregadores que condicionam, desde muito cedo, uma forte desigualdade de oportunidades escolares/sociais no Brasil.

\section{Referências bibliográficas}

ALMEIDA, Ana Maria F. Uma escola para a elite paulista. In: NOGUEIRA, Maria Alice; ALMEIDA, Ana Maria F. (Orgs.). A Escolarização das Elites: um panorama internacional da pesquisa. Petrópolis: Vozes, 2002.

ALVES, Maria Teresa G.; SOARES, José Francisco. Efeito-escola e estratificação escolar: o impacto da composição de turmas por nível de habilidade dos alunos. Educação em Revista, v. 45, 2007. 
BIBLARZ, Timothy J. Family Structure, Educational Attainment, and Socioeconomic Success: Rethinking the Pathology of Matriarchy". International Sociological Association (ISA), Research Committee 28 on Social Stratification and Mobility (http://www.soc.duke.edu/ rc28/). Conference Paper, Madison, 1999.

BRANDAO, Zaia. Elites Escolares e Capital Cultural. Boletim Soced, PUC-Rio, n. 3, 2006a. BRANDAO, Zaia. A Produção das Elites Escolares. Educação On Line, PUC-Rio, n. 2, 2006b.

BRANDAO, Zaia; MANDELERT, Diana; PAULA, Lucília de. A Circularidade Virtuosa: investigação sobre duas escolas no Rio de Janeiro. Cadernos de Pesquisa, São Paulo, v. 35, n. 126, p. 747-758, 2005.

COSTA, Marcio; SILVA, Graziella M. D. Amor e Desprezo: o velho caso entre sociologia e educação no âmbito do GT-14. Revista Brasileira de Educação, Campinas, n. 22, 2003. ELIAS, Norbert; SCOTSON, John. Os estabelecidos e os Outsiders. Sociologia das relações de poder a partir de uma pequena comunidade. Rio de Janeiro: Zahar, 2000.

NOGUEIRA, Maria Alice. Uma dose de Europa ou Estados Unidos para cada filho: estratégias familiares de internacionalização dos estudos. Pro-posições, Campinas, v. 9, n. 1[25], 1998a.

NOGUEIRA, Maria Alice. A escolha do estabelecimento de ensino pelas famílias: a ação discreta da riqueza cultural. Revista Brasileira de Educação, São Paulo, v. 1, n. 7, 1998b.

NOGUEIRA, Maria Alice. Relação família-escola: novo objeto da Sociologia da Educação. Paidéia, Ribeirão Preto, v. 8, n. 14/15, 1999.

NOGUEIRA, Maria Alice. Estratégias de escolarização em famílias de empresários. In: ALMEIDA, A.; NOGUEIRA, Maria Alice (Orgs.). A escolarização das elites - um panorama internacional da pesquisa. Petrópolis: Vozes, 2002.

NOGUEIRA, Maria Alice. Favorecimento econômico e excelência escolar: um mito em questão. Revista Brasileira de Educação, Rio de Janeiro, n. 26, 2004.

TAVARES Jr., Fernando. Limites Sociais da Educação no Brasil: Estratificação, Mobilidade Social e Ensino Superior. Tese (Doutorado) IUPERJ, 2007.

ZAGO, Nadir. Do acesso à permanência no ensino superior: percursos de estudantes universitários de camadas populares. Revista Brasileira de Educação, Campinas, v. 11, n. 32, 2006.

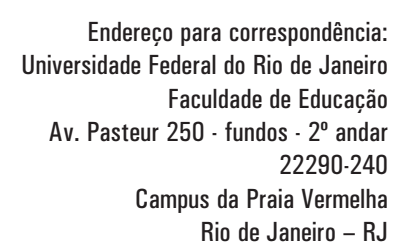

Data de recebimento: 04/03/2009

Data de aprovação: 14/01/2010 